\title{
Reatividade ao Automonitoramento em uma Portadora da Síndrome do Intestino Irritável
}

Carlos Henrique Bohm

Lincoln da Silva Gimenes ${ }^{1}$

Universidade de Brasilia

\begin{abstract}
RESUMO - O automonitoramento (AM) é usado para a observação, avaliação e intervenção em problemas comportamentais e de saúde. Neste estudo, utilizou-se AM na avaliação de comportamentos de uma mulher de 44 anos de idade com a síndrome do intestino irritável (SII). Durante um período de 19 semanas a paciente preencheu formulários diários de AM de atividades diárias, sintomas intestinais e consumo alimentar. Uma melhora não programada nos sintomas foi observada, que pode ser explicada como um efeito de reatividade ao AM. Inicialmente as atividades diárias da paciente aconteciam de forma ininterrupta e eram associadas à constipação intestinal; com a ajuda de AM ela aprendeu a realizar interrupções dessas atividades quando dos sinais de motilidade intestinal, aumentando assim a frequência de evacuação.
\end{abstract}

Palavras-chave: automonitoramento, reatividade, síndrome do intestino irritável, análise funcional.

\section{Reactivity to Self-Monitoring in a Patient Diagnosed with Iirritable Bowel Syndrome}

\begin{abstract}
Self-monitoring (SM) is used for observation, assessment and intervention in behavioral and health problems. In this study SM was used in the behavior assessment of a 44 year old female with an irritable bowel syndrome (IBS). During a period of 19 weeks this patient filled in daily SM forms related to general activities, bowel functioning and food intake, A not foreseen improvement of the symptoms was observed, which can be explained as a reactivity effect to SM. Initially, the activities of the participant occurred in a uninterruptedly manner and were associated with bowel constipation; with the SM recording the participant learned to interrupt her activities as response to signals of bowel movements, increasing, therefore, the frequency of defecation.
\end{abstract}

Keywords: self-monitoring, reactivity, irritable bowel syndrome. functional analysis.

Auto-monitoramento (AM) é o comportamento de observar e registrar sistematicamente a ocorrência de algum comportamento (privado ou público) emitido pela própria pessoa e eventos ambientais associados. Para Korotitsch e Nelson-Gray (1999) o AM envolve a discriminação da ocorrência do comportamento e a produção do seu registro, bem como de informações adicionais. Um exemplo é escrever em um diário os horários das refeições, alimentos ingeridos, sentimentos e eventos antecedentes e conseqüentes.

Geralmente os comportamentos-problema de um cliente estão sob controle de variáveis que não são óbvias ou que não estão presentes no contexto da terapia. Dentre as técnicas de observação e avaliação, o AM é uma das alternativas mais flexíveis, baratas e que exigem menos recursos clínicos para a coleta de dados. O AM é usado como forma de avaliação durante todo o processo terapêutico para clarificação do diagnóstico, condução de análises funcionais, delimitação dos objetivos da intervenção, planejamento de cada sessão e da intervenção como um todo, e avaliação do progresso da terapia e do seu resultado final (Korotitsch \& Nelson-Gray, 1999).

1 Endereço para correspondência: Universidade de Brasília. Instituto de Psicologia. Departamento de Processos Psicológicos Básicos. Campus Universitário Darcy Ribeiro. Brasília, DF. CEP 70910-900.

E-mail:1gimenes@unb.br; bohm.carlos@gmail.com
Algumas das diversas respostas automonitoradas para a avaliação comportamental e outros tipos de avaliação são: comportamentos presentes na síndrome do intestino irritável (SII) (Latimer, 1988), intensidade da dor em pacientes com artrite e dores de cabeça (Barton, Blanchard \& Veazey, 1999), comportamentos públicos e encobertos em situações de exposição oral geradoras de ansiedade (Oliveira \& Duarte, 2004), sentimentos envolvidos no transtorno do pânico combinado com agorafobia (Britto \& Duarte, 2004), registro do peso corporal e consumo alimentar (Bezerra, 2001) e comportamento de fumar, seus antecedentes, nível de ansiedade e pensamentos relacionados (Mundim \& Bueno, 2006). Esta lista não é exaustiva e muitos outros exemplos poderiam ser inseridos.

$\mathrm{O}$ uso do AM pode produzir o efeito de reatividade, no qual ocorre a alteração da freqüência do comportamento-alvo, geralmente na direção desejável, ou seja, reduzindo a freqüência de comportamentos indesejáveis e/ou aumentando a de comportamentos desejáveis sem nenhuma outra intervenção. Na explicação de Nelson e Hayes (1981) para a reatividade, o processo inteiro de AM (instruções do terapeuta, treino em AM, o dispositivo de registro, comentários dos outros sobre o dispositivo e as respostas monitoradas) sinaliza as prováveis conseqüências ambientais que resultam em mudança de comportamento. Essa proposição explica casos em que a mudança de comportamento não está ligada 
a respostas de AM, como baixa acurácia no registro, baixa freqüência do comportamento alvo e pouca utilização do instrumento de registro.

Os resultados do experimento de Hayes e Nelson (1983) ajudam a melhor explicar essa hipótese de que a reatividade não depende exclusivamente da resposta monitorada, mas sim de todo o procedimento de AM. Durante a linha de base os participantes assistiam um vídeo e observadores registravam o número de vezes que a pessoa tocava a sua própria face. Logo em seguida, na fase experimental, os participantes do grupo AM foram instruídos a pressionar um interruptor toda vez que tocassem a própria face. O grupo com dicas externas contingentes deveria pressionar o interruptor toda vez que fosse projetada a mensagem "por favor não toque sua face". Este grupo equivale a um AM com acurácia. A mensagem aparecia quando os observadores registravam que a pessoa tocou a sua face. $\mathrm{O}$ grupo com dicas externas não contingentes foi submetido às mesmas condições, exceto pelo fato que a mensagem aparecia uma vez a cada dois minutos, independentemente dos comportamentos do participante. Este grupo equivale a um AM sem acurácia. Ocorreram efeitos reativos semelhantes para os três grupos, isto é, houve uma redução no número de respostas de tocar a face na fase experimental em relação à linha de base. Os dados tornam mais plausível a idéia de que a reatividade ocorre pelo valor da dica fornecida pelo próprio AM.

Existem diversos relatos do efeito de reatividade ao AM e sua efetividade em controlar o comportamento monitorado. Alguns exemplos são: ingestão alimentar (Bezerra, 2001), atividade de nadar (Polaha, Allen \& Studley, 2004), fumar (Abrams \& Wilson, 1979) e transtorno de estresse pós-traumático (Tarrier, Sommerfield, Reynolds \& Pilgrim, 1999), entre outros.

Maletzky (1974) apresenta os dados de cinco participantes que desejavam modificar seus comportamentos. Esses participantes utilizaram um contador de pulso como instrumento de registro. Diariamente cada participante marcava em um gráfico o total de ocorrências do comportamento previamente definido para ser monitorado. Para todos os participantes, os comportamentos, que variavam desde arranhar a pele, roer unhas e tiques faciais, diminuíram de freqüência após o início do AM. Depois da retirada gradual do contador de pulso houve uma longa e duradoura remissão dos comportamentos. $\mathrm{O}$ autor concluiu que a mera contagem do comportamento, sem nenhum outro tipo de intervenção, foi suficiente para reduzir a frequência dos comportamentos monitorados.

Frederiksen (1975) descreveu o caso de uma mulher com episódios de pensamento recorrente cujo tema era câncer de estômago e de mama. Na primeira fase ela anotava em um gráfico apenas a freqüência de episódios. Ao longo da primeira semana houve um rápido declínio da freqüência, que se manteve estável durante os dias seguintes. A taxa média nessa fase foi de dois episódios por dia. $\mathrm{Na}$ fase seguinte, de monitoramento intensivo, eram registrados também o horário e a duração do episódio, atividade pública, pensamentos antecedentes, o conteúdo dos episódios, a severidade e os eventos que os seguiam. Houve um declínio adicional no número de episódios e ocorreram somente cinco episódios nos últimos 25 dias de registro, isto é, o efeito de reatividade ao AM foi maior na fase em que se exigiu um AM mais intensivo. Nenhum episódio foi relatado em quatro meses de seguimento.

Latner e Wilson (2002) verificaram o efeito do AM sobre a freqüência de episódios de excesso alimentar em mulheres com bulimia nervosa e hiperfagia episódica (binge eating disorder). Os dados registrados foram: tipo e quantidade estimada de comida e bebida ingeridas, hora e lugar da ingestão, se consideraram uma refeição, um lanche ou um excesso, se houve uma perda de controle sobre o comer, e pensamentos e emoções relacionados ao comer. A média do número de episódios de excesso alimentar reduziu de 0,91 por dia (linha de base) para 0,41 (AM).

Em conjunto, as pesquisas sobre o efeito de reatividade ao AM mostram que o fenômeno tem generalidade, pois ocorre com pessoas de diferentes idades, em diferentes contextos e com uma variedade de comportamentos (ver mais relatos de pesquisas em Bohm \& Gimenes, 2008; 2009 e Korotitsch \& Nelson-Gray, 1999).

Nos estudos sobre SII, o AM foi utilizado para avaliar os sintomas antes e depois de intervenções (Leibbrand \& Hiller, 2003) e para identificar correlações entre estresse e sintomas (Levy, Cain, Jarrett \& Heitkemper, 1997), mas não se conhece relatos do efeito de reatividade ao AM nos portadores dessa síndrome.

A SII é um transtorno gastrintestinal funcional no qual há desconforto ou dores abdominais recorrentes e a modificação na freqüência de evacuação (Mizputen et al., 2006). Os pacientes podem apresentar inchaço abdominal, fezes aquosas, endurecidas, eliminação excessiva de gases, dificuldades em eliminar gases e sensação de evacuação incompleta. O quadro sintomático pode ter predomínio de diarréia, de constipação ou de alternância entre os dois. Também geralmente é inclusa como critério diagnóstico a ausência de um substrato orgânico estrutural evidente (Passos et al. 2006) como inflamação, parasita ou deficiência de enzima (Whitehead \& Bosmajian, 1982) que melhor expliquem os sintomas.

O objetivo desta pesquisa foi realizar uma análise funcional dos sintomas da SII bem como dos possíveis efeitos de reatividade ao AM. Para tanto, utilizou-se o AM para registrar as atividades da vida diária e os sintomas relacionados à SII em uma participante portadora dessa síndrome.

\section{Método}

\section{Participante}

Mediante o encaminhamento de um médico gastroenterologista do Hospital Universitário de Brasília, a participante foi convidada pelo pesquisador, via chamada telefônica, para uma entrevista inicial. Esse contato foi realizado depois da aprovação do projeto de pesquisa pelo Comitê de Ética da Faculdade de Saúde da Universidade de Brasília.

Os critérios utilizados para a inclusão da participante na pesquisa foram: a) receber o diagnóstico de SII de um médico gastroenterologista sob os critérios de Roma III (Mizputen et al. 2006); b) não estar, ou suspender tratamento medicamentoso específico para a SII durante o período de coleta de dados, com o aval do médico responsável; c) não estar em 
processo de psicoterapia por transtornos comportamentais ou psiquiátricos graves; d) não ser portadora de doenças orgânicas relacionadas ao trato gastrointestinal.

As sessões para coleta de dados ocorreram no Hospital Universitário de Brasília, em uma sala especificamente designada para esse fim. Para fins de apresentação dos dados a participante foi caracterizada com um nome fictício de Penélope. As informações de identificação da participante se referem às condições da mesma no início da pesquisa.

Penélope estava com 44 anos de idade, possuía ensino médio completo, havia trabalhado durante 13 anos como auxiliar de disciplina escolar e no momento da pesquisa se dedicava exclusivamente aos afazeres domésticos. A participante morava com o companheiro (com quem estava em união estável há 25 anos), tinha um filho de 21 anos, uma filha casada de 24 anos e um neto de dois anos, para o qual assumia os cuidados quando os pais da criança estavam trabalhando. Os filhos de Penélope trabalhavam e não moravam mais com a mesma.

\section{Materiais e instrumentos}

$\mathrm{Na}$ coleta de dados foram utilizados um roteiro de entrevista semi-estruturada para SII (Bohm, 2009), uma adaptação do Questionário Construcional de Goldiamond (Gimenes, Andronis \& Layng, 2005) e formulários de AM (Bohm, 2009). No formulário do funcionamento intestinal, era feito o registro de cada evacuação, seu horário e duração, local e aspecto das fezes. No formulário para as atividades diárias, eram registradas diversas atividades diárias (refeições, atividades físicas, estudo, trabalho, lazer e outras que fossem avaliadas como relevantes), seus horários e durações, pessoas presentes, eventos que ocorriam após essas atividades e sentimentos e sensações envolvidas. No formulário do consumo alimentar, foi registrado o tipo de refeição, os alimentos e bebidas consumidos e a quantidade de cada um.

\section{Procedimentos}

Sessões. Foram realizadas duas entrevistas iniciais semi-estruturadas com duração de 90 minutos. O Questionário Construcional de Goldiamond guiou, de forma geral, a coleta dos seguintes dados: história de vida, histórico médico, tratamentos, sintomas da SII, déficits e excessos comportamentais e suas variáveis mantenedoras, repertórios comportamentais adequados, entre outros. A entrevista semi-estruturada teve como objetivo coletar dados específicos e detalhados sobre: a) freqüência, severidade, duração, contexto de ocorrência e há quanto tempo ocorrem os sintomas da SII e outras complicações de saúde relacionadas; b) grau de comprometimento de atividades da vida diária; c) sensações e sentimentos relacionados aos sintomas; e d) medicamentos utilizados, tempo de uso e dosagem. Nessas entrevistas iniciais a participante recebeu e assinou um Termo de Consentimento Livre e Esclarecido e recebeu informações a respeito da realização da pesquisa.

Após as duas entrevistas iniciais, foram realizadas 15 sessões semanais, com duração média de 73 minutos, num período de 94 dias. Essas sessões tiveram como objetivos: (a) fazer uma leitura dos registros nos formulários de AM de cada semana; (b) esclarecer pontos confusos nos registros; (c) corrigir erros nos mesmos; (d) esclarecer aspectos gerais da vida diária que não eram registrados e (e) consequenciar positivamente comportamentos compatíveis com AM acurado, tais como: seguir as instruções de preenchimento dos formulários e relato de execução dos registros temporalmente próximos à ocorrência dos comportamentos. Esse reforço verbal potencial consistia em: elogios, explicação da importância do AM para a avaliação comportamental e informação de que o engajamento da participante na pesquisa seria importante para o desenvolvimento de pesquisas futuras que talvez pudessem resultar em benefícios nas vidas de outras pessoas. Observou-se que essas consequências verbais do pesquisador garantiram, de uma forma geral, a adesão inicial da participante à pesquisa.

Automonitoramento. No final da segunda entrevista a participante recebeu treino sobre como preencher os formulários (recebeu instruções, em seguida fez alguns registros e o pesquisador avaliou os mesmos, reforçando os registros adequados e corrigindo os registros imprecisos). A participante foi, então, instruída para fazer registros diários até o final da pesquisa.

No formulário para registro do funcionamento intestinal era feito pelo menos um registro por dia, assinalando a ocorrência de alguns sintomas da SII. Quando ocorria mais de uma evacuação no mesmo dia, um novo registro era feito. No formulário para as atividades diárias, a participante recebeu sugestões de quais atividades poderia registrar e também teve a liberdade para escolher quaisquer outras que desejasse registrar. O registro do consumo alimentar foi utilizado para avaliar a relação entre o consumo de fibras e os sintomas da SII. Penélope fez esse registro por um período 21 dias, a partir do $20^{\circ}$ dia do início dos registros de atividades diárias e do funcionamento intestinal. Uma nutricionista avaliou a precisão das medidas dos alimentos e da descrição dos tipos de alimentos. Depois dessa avaliação o pesquisador esclareceu alguns registros imprecisos com a participante. $\mathrm{O}$ consumo diário de fibras totais, de fibras solúveis e de fibras insolúveis foi aferido. Essa mensuração foi feita utilizando-se a tabela brasileira de composição dos alimentos (Núcleo de Estudos e Pesquisas em Alimentação da Universidade de Campinas, 2006), a tabela de composição de alimentos (Philippi, 2002) e o software Avanutri (Avanutri, 2008). Foram realizados cálculos de correlação entre o consumo de fibras de cada dia e os sintomas do mesmo dia e do dia seguinte.

Entrevista devolutiva. Após o término da análise dos dados da pesquisa, foi conduzida uma sessão em que a participante recebeu a análise dos seus dados e pode expressar suas opiniões sobre a pesquisa e esclarecer possíveis dúvidas.

\section{Resultados}

\section{Análise do histórico clínico}

A mãe da participante Penélope faleceu quando ela tinha quatro anos. Até os 12 anos morou com o pai na zona rural e em seguida foi morar com uma tia, que se propôs a custear 
sua subsistência e sua educação em troca de Penélope cumprir rigorosamente todos os afazeres domésticos. A tia fornecia elogios e atenção contingentes ao comportamento de lavar a louça da forma como exigia da sobrinha.

Quando adulta, o companheiro da participante Penélope a traiu explicitamente diversas vezes, sempre se negou a se casar e passou por períodos de alcoolismo durante os quais a agredia fisicamente. A ausência de uma figura materna, um pai desatento e um relacionamento conjugal de 25 anos com poucas interações afetivas sugerem um estado antigo e permanente de privação de atenção e afeto.

Penélope geralmente se engajava em comportamentos que iam contra sua vontade, tais como: emprestar dinheiro, deixar de cobrar as dívidas, cozinhar para visitas (familiares e amigos do companheiro) que chegavam à sua casa sem aviso prévio e manter práticas sexuais sem preservativo com o companheiro. Atender pedidos abusivos aumentava suas demandas de trabalho, o que ocupava a maior parte do seu tempo, mas evitava o desagrado das pessoas. Os reforçadores sociais pareciam manter também seu comportamento de se queixar sobre saúde. Na sua família, por exemplo, Penélope se tornou conhecida como uma pessoa que adorava hospitais.

Além das dificuldades nos relacionamentos interpessoais, Penélope apresentava alguns comportamentos-problema na realização de suas atividades domésticas, como a ritualização na tarefa de lavar louça. Quando a cadeia comportamental era interrompida pela chegada de alguma visita na sua casa ou por ter que sair de casa para fazer algum favor (principalmente à filha), ela tinha que reiniciar a cadeia pelo início da lavagem das louças. Penélope tinha uma preocupação predominante com a limpeza das panelas de alumínio, que, depois de cada refeição, “devem ser areadas até ficarem como espelhos". Quando esfregava muito essas panelas, sentia dores nos pulsos e braços. O início do hábito de lavar as louças da forma descrita datava da época em que foi morar com a tia aos 12 anos e parecia ter remissão temporária quando as dores nos pulsos e braços aumentam. $\mathrm{O}$ padrão obsessivo se estendia, em menor grau, para a organização de guarda-roupas e de comprovantes do pagamento de contas da família. Os comportamentos de limpeza e organização da participante tornaram-na conhecida como uma pessoa caprichosa e perfeccionista, atributos valorizados na escola em que trabalhava.

A principal queixa da participante Penélope era a constipação, com a evacuação variando em torno de uma a três vezes por semana. O bolo fecal era predominantemente endurecido, no formato de pequenos caroços. Algumas vezes a eliminação de um bolo fecal endurecido era sucedida, no mesmo dia, por uma ou duas evacuações de fezes amolecidas. Com o aumento do tempo de constipação aumentavam os seguintes sintomas: dor abdominal, inchaço abdominal, dificuldade para andar, dor torácica, pouca eliminação de gases, presença de muco e sangue nas fezes, dor anal ao evacuar, sensação de evacuação incompleta, sensação de "peso no estômago" e ânsia de vômito após as refeições. A evacuação intestinal reduzia a maior parte desses sintomas. Quando fora de casa, eventualmente a participante sentia urgência em evacuar, porém na maioria das vezes evitava se dirigir ao toalete. Os sintomas da SII haviam surgido há aproxima- damente 15 anos e não foi possível detectar nenhum evento associado a esse início. No momento da pesquisa Penélope havia deixado de trabalhar em uma escola há quatro meses e passou a evacuar mais desde então.

Além dos sintomas da SII, Penélope tinha gastrite (para a qual usava um comprimido de Omeprazol $20 \mathrm{mg}$. diariamente), suspeita de artrite (queixa de dores nas pernas, braços e pulsos) e esofagite. Ela já havia tido enxaqueca, a qual entrou em remissão havia três anos por meio de tratamento médico (AM e medicamento amitriptilina). Sob orientação médica, a participante tentou remediar a constipação com alteração da dieta, mas não obteve sucesso.

Antes do inicio da pesquisa, Penélope se sentia angustiada nos dias em que estava muito ocupada com os afazeres domésticos. Algumas vezes sentia urgência em evacuar durante alguma atividade como preparar refeições, lavar a louça e alimentar-se, entre outras. No entanto, ela não interrompia essas atividades para ir ao toalete, pois as realizava ininterruptamente até a atividade estar completa e, quando terminava, já não conseguia mais evacuar.

No repertório da participante Penélope fica bem evidenciado um padrão comportamental composto por pensamentos obsessivos, rituais compulsivos, rigidez na execução de atividades e perfeccionismo. A forma ininterrupta e inflexível de realização das atividades domésticas tem paralelo com comportamentos mantidos por esquemas de razão fixa e é um padrão associado ao aumento do tempo de constipação.

A Figura 1 apresenta o número de ocorrência diária de evacuações. Ao longo do período de AM, o número de ocorrência diária de evacuações aumentou gradativamente (o que também pode ser visualizado na linha de tendência na figura). Esse aumento pode ser considerado um efeito que tem sido descrito pela literatura como reatividade ao AM (haja visto que não foi conduzida nenhuma intervenção nesse período que poderia explicar essa mudança).

Penélope relatou que, à medida que começou a fazer o AM das atividades diárias e dos sintomas, passou a interromper suas atividades domésticas quando sentia urgência em evacuar. Para mensurar essas interrupções foram analisadas todas as atividades anteriores e posteriores a cada episódio de evacuação. A Tabela 1 descreve as atividades anteriores e posteriores aos episódios de evacuação, pertencentes ao mesmo tipo de atividade, isto é, representam atividades que foram interrompidas para idas ao toalete. Antes de fazer AM, a participante não interrompia essas atividades mesmo quando sentia necessidade de evacuação. A título de comparação, na Tabela 2 é apresentada uma amostra dos dados de descrição das atividades anteriores e posteriores pertencentes a atividades diferentes. Normalmente os episódios de evacuação ocorriam somente entre diferentes atividades, ou seja, a participante somente se dirigia ao toalete após terminar alguma atividade, e em seguida iniciava outra atividade diferente.

Nota-se na Figura 2 que, aproximadamente a partir do $50^{\circ}$ dia, tornou-se mais frequente o repertório de interrupção das atividades semelhantes para idas ao toalete. A média diária do número de evacuações antes do $50^{\circ}$ dia foi 0,63 e depois do $50^{\circ}$ dia foi 0,90 . Esta diferença entre as médias significa um aumento de cerca de $30 \%$ das evacuações no período após o $50^{\circ}$ dia. 


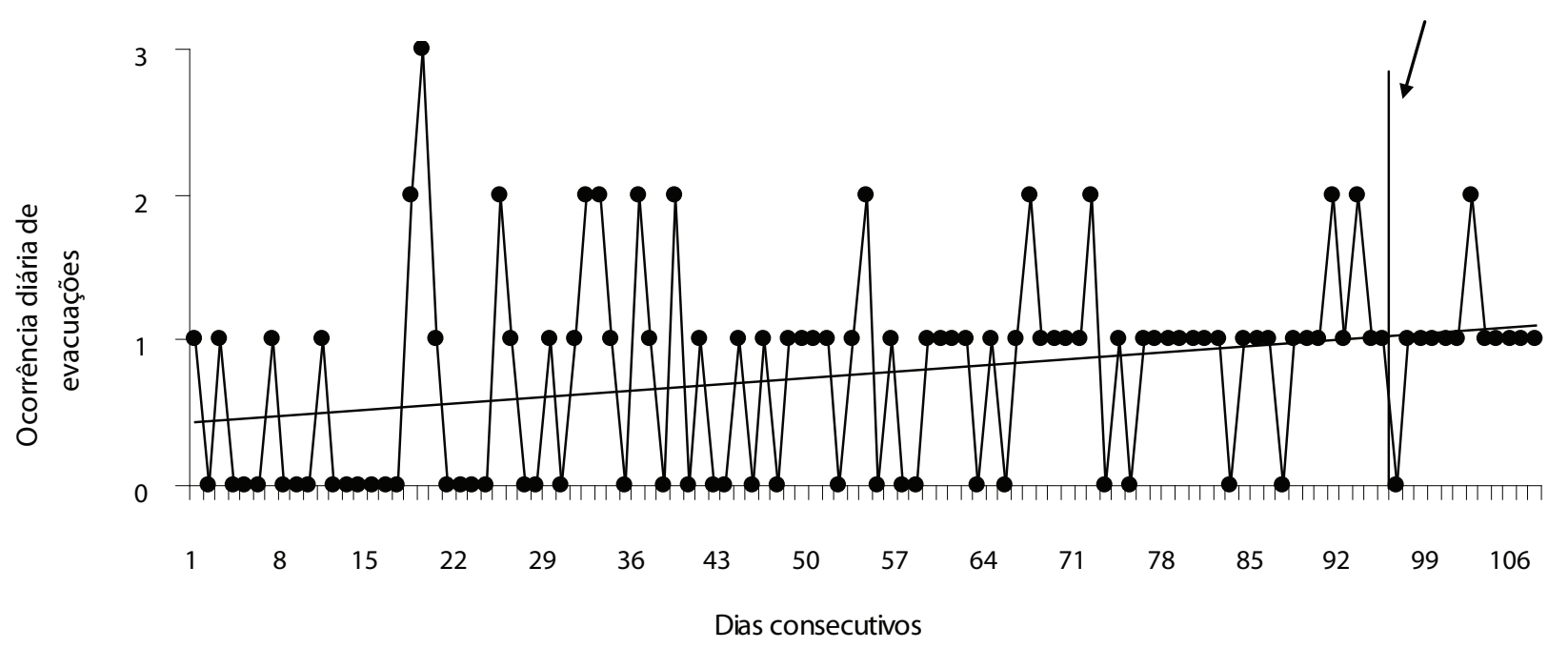

Figura 1. Número de ocorrência diária de evacuações. A seta indica o início da intervenção.

A Figura 2 mostra a porcentagem de evacuações que ocorreram entre atividades semelhantes e de evacuações que ocorreram entre atividades diferentes, em relação ao total de evacuações, antes e depois do $50^{\circ}$ dia de AM. Em relação ao total de evacuações em cada período, a porcentagem de evacuações que ocorreram entre atividades semelhantes foi 9,7\% antes do $50^{\circ}$ dia e $36,5 \%$ depois do $50^{\circ}$ dia. Ou seja, houve um aumento na proporção de evacuações que ocorreram entre atividades semelhantes. Em relação ao total de evacuações em cada período, a porcentagem de evacuações que ocorreram

Tabela 1. Descrição das atividades anteriores e posteriores aos episódios de evacuação referentes ao mesmo tipo de atividade.

\begin{tabular}{lll}
\hline Dia & $\begin{array}{l}\text { Atividade anterior à } \\
\text { evacuação }\end{array}$ & $\begin{array}{l}\text { Atividade posterior à } \\
\text { evacuação }\end{array}$ \\
\hline 3 & Assistir televisão & Assistir televisão \\
19 & Preparar lanche & Tomar chá \\
25 & Preparar o jantar & Jantar \\
50 & Preparar café da manhã & Tomar café da manhã \\
51 & Preparar lanche & Lanchar \\
54 & Tomar banho & Voltar a tomar banho \\
61 & Tomar banho & Tomar outro banho \\
64 & Arrumar a cozinha & Fazer faxina \\
66 & Preparar café da manhã & Tomar café da manhã \\
67 & Arrumar-se para sair de casa & Sair de casa \\
68 & Preparar café da manhã & Tomar café da manhã \\
72 & Cozinhar & Cozinhar \\
74 & Lavar louça & Fazer faxina \\
78 & Tomar café da manhã & Lavar louça \\
86 & Preparar o jantar & Jantar \\
88 & Estar no centro de saúde & Voltar ao centro de saúde \\
89 & Molhar as plantas & Lavar a garagem \\
91 & Lavar a louça & Arrumar a cozinha \\
\hline
\end{tabular}

entre atividades diferentes foi $87 \%$ antes do $50^{\circ}$ dia e $65,4 \%$ depois do $50^{\circ}$ dia. Isto é, houve um declínio na proporção de evacuações que ocorreram entre atividades diferentes. Em resumo, a figura mostra que antes do $50^{\circ}$ dia a participante raramente interrompia suas atividades para idas ao toalete, o que se tornou mais freqüente após o $50^{\circ}$ dia. $\mathrm{O}$ aumento no número de evacuações que ocorreram entre atividades semelhantes (comparando os períodos antes e depois do $50^{\circ}$ dia) foi acompanhado de um aumento geral dessas ocorrências, apesar da diminuição das mesmas entre atividades diferentes.

Em relação à alimentação, foi observada uma correlação significativa moderada e positiva entre o consumo de fibras solúveis $(\mathrm{N}=21$ dias $)$ e a ocorrência de dor abdominal $(\mathrm{r}=$ $0,57, p<0,05$ ). Tendo em vista que o consumo de fibras aumenta a motilidade intestinal e a participante muitas vezes não ia ao toalete quando sentia necessidade de evacuação, provavelmente os gases oriundos da ingestão de fibras acumulavam no intestino, produzindo dor abdominal. Em resumo, a reatividade ao AM envolveu uma alteração de rotina (interrupção da atividade para idas ao toalete), que por sua vez contribuiu para uma melhora na regularização e aumento da atividade intestinal.

Tabela 2. Amostra da descrição das atividades anteriores e posteriores aos episódios de evacuação referentes a atividades diferentes.

\begin{tabular}{lll}
\hline Dia & $\begin{array}{l}\text { Atividade anterior à } \\
\text { evacuação }\end{array}$ & $\begin{array}{l}\text { Atividade posterior à } \\
\text { evacuação }\end{array}$ \\
\hline 11 & Arrumar a cozinha & Dar banho no neto \\
19 & Dormir & Preparar café da manhã \\
32 & Receber visita & Recolher a roupa do varal \\
36 & Assistir televisão & Preparar refeição \\
48 & Tomar café da manhã & Molhar as plantas \\
62 & Preparar café da manhã & Arrumar-se para sair \\
80 & Assistir televisão & Vestir o neto \\
90 & Colocar roupas no varal & Preparar refeição \\
\hline
\end{tabular}



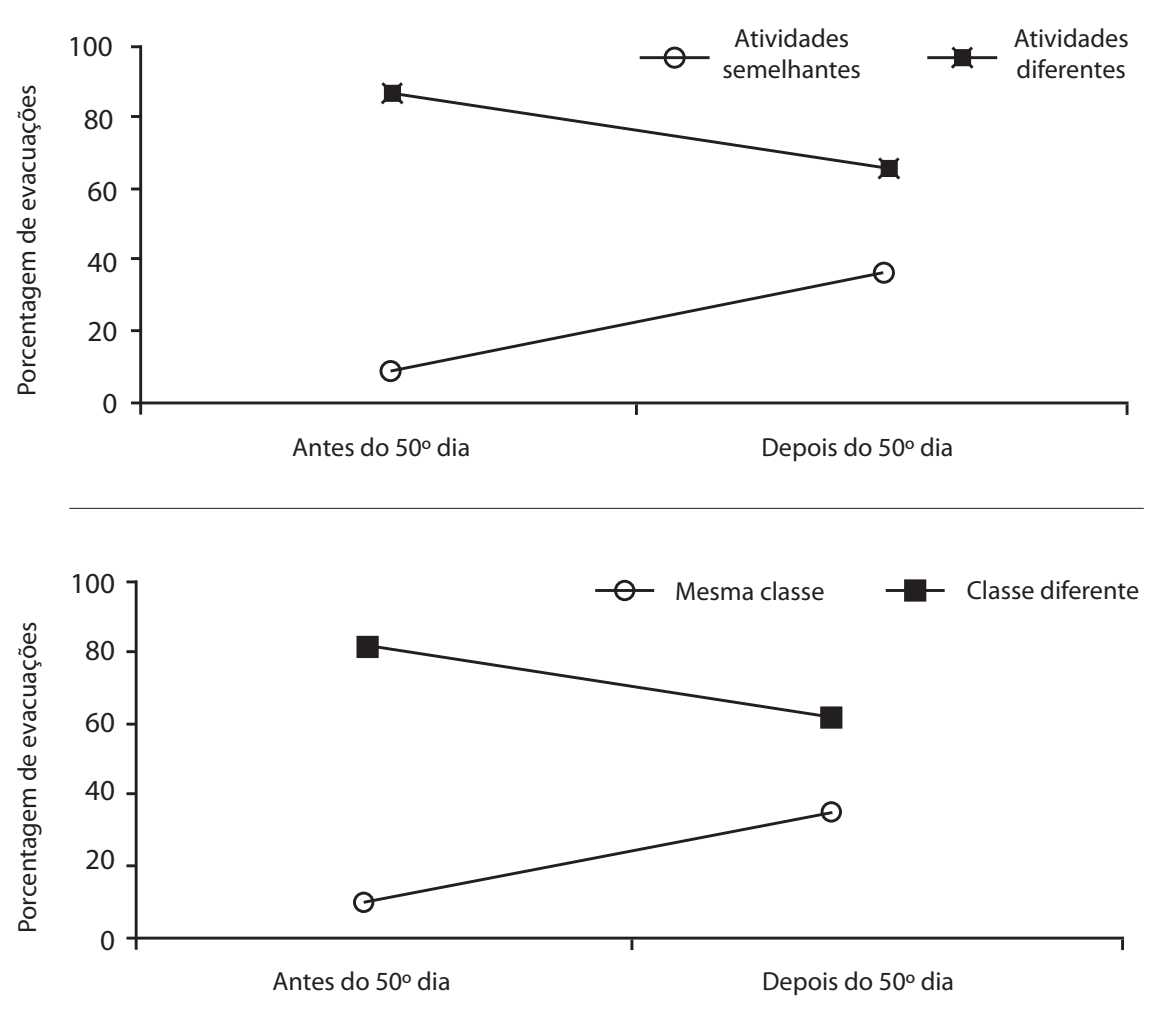

Figura 2. Porcentagem de evacuações que ocorreram entre atividades semelhantes e de evacuações que ocorreram entre atividades diferentes, em relação ao total de evacuações, antes e depois do $50^{\circ}$ dia de $\mathrm{AM}$.

\section{Discussão}

O caso da participante Penélope representa um caso de reatividade ao $\mathrm{AM}$, tendo havido um aumento gradual da freqüência de evacuação ao longo dos registros dos sintomas da SII e das atividades diárias. O procedimento de AM produziu um consequente efeito de reatividade sobre a freqüência de evacuação.

Durante o dia Penélope escrevia em uma folha de rascunho as atividades diárias realizadas e suas durações. Ao final do dia ela transcrevia essas informações para os formulários fornecidos pelo pesquisador e inseria as outras informações necessárias que não havia registrado durante o dia. Ela relatou que se esforçava para escrever com letra bonita e com o mínimo possível de rasuras. Uma inspeção visual nos formulários revelou que, em comparação com os registros iniciais, os registros finais eram mais específicos, com menos rasuras e com uma letra mais legível. Esses comportamentos relacionados ao AM possibilitaram um tempo de auto-observação que não existia antes de Penélope participar da pesquisa. Esses dados corroboram o achado de Frederiksen (1975), que relatou um caso em que o efeito de reatividade ao AM foi maior na fase em que se exigiu um AM mais intensivo, isto é, registrando um maior número de informações sobre o comportamento-alvo (pensamento recorrente sobre câncer). O caso apresentado por Frederiksen e o caso da participante Penélope revelam que o aumento do tempo de auto-observação por meio do AM esteve associado com a diminuição dos comportamentos-problema.

A reatividade ao AM observada em Penélope vai a favor, também, da explicação de Nelson e Hayes (1981) e Hayes e Nelson (1983). Esses autores sugerem que o processo de
AM, como um todo, sinaliza as prováveis alterações ambientais que são produzidas pela mudança da freqüência do comportamento registrado. Ou seja, o procedimento de AM para a participante Penélope sinalizava que a interrupção das suas rotinas (que anteriormente eram extremamente rígidas) resultava em um aumento da freqüência de evacuação, em uma melhora dos sintomas da SII e em reforço verbal do pesquisador para o comportamento de auto-registro. O caso de Penélope pode subsidiar o uso do AM em portadores de SII que podem se beneficiar do efeito de reatividade.

Parte dos dados observados no caso de Penélope pode ser entendida por meio do modelo de motilidade intestinal induzida por contingências de reforçamento (cf. Gimenes, 1997 e Gimenes, Brandão \& Benvenuti, 2005). Os comportamentos induzidos por contingências (ou comportamentos adjuntivos) são específicos aos esquemas de reforçamento, mas o reforço não é contingente a esses comportamentos. Esse tipo de comportamento geralmente é induzido de forma excessiva por esquemas temporais de reforçamento em comparação com esquemas de reforçamento contínuo ou de razão. Alguns exemplos desses comportamentos são: ingestão de água, drogas e alimento, roer materiais não comestíveis, motilidade intestinal, atividade motora, agressão, entre outros (Falk \& Kupfer, 1998; Gimenes, Brandão \& Benvenuti, 2005).

A indução da motilidade intestinal em ratos foi observada com a manipulação de esquemas de reforçamento em FI e VI (Rayfield, Segal \& Goldiamond, 1982; Gimenes, Andronis \& Goldiamond, 1987), esquema múltiplo de reforçamento FI-CRF (Gimenes, Andronis \& Goldiamond, 1988), esquema de liberação de alimento em FT (Wyle, 

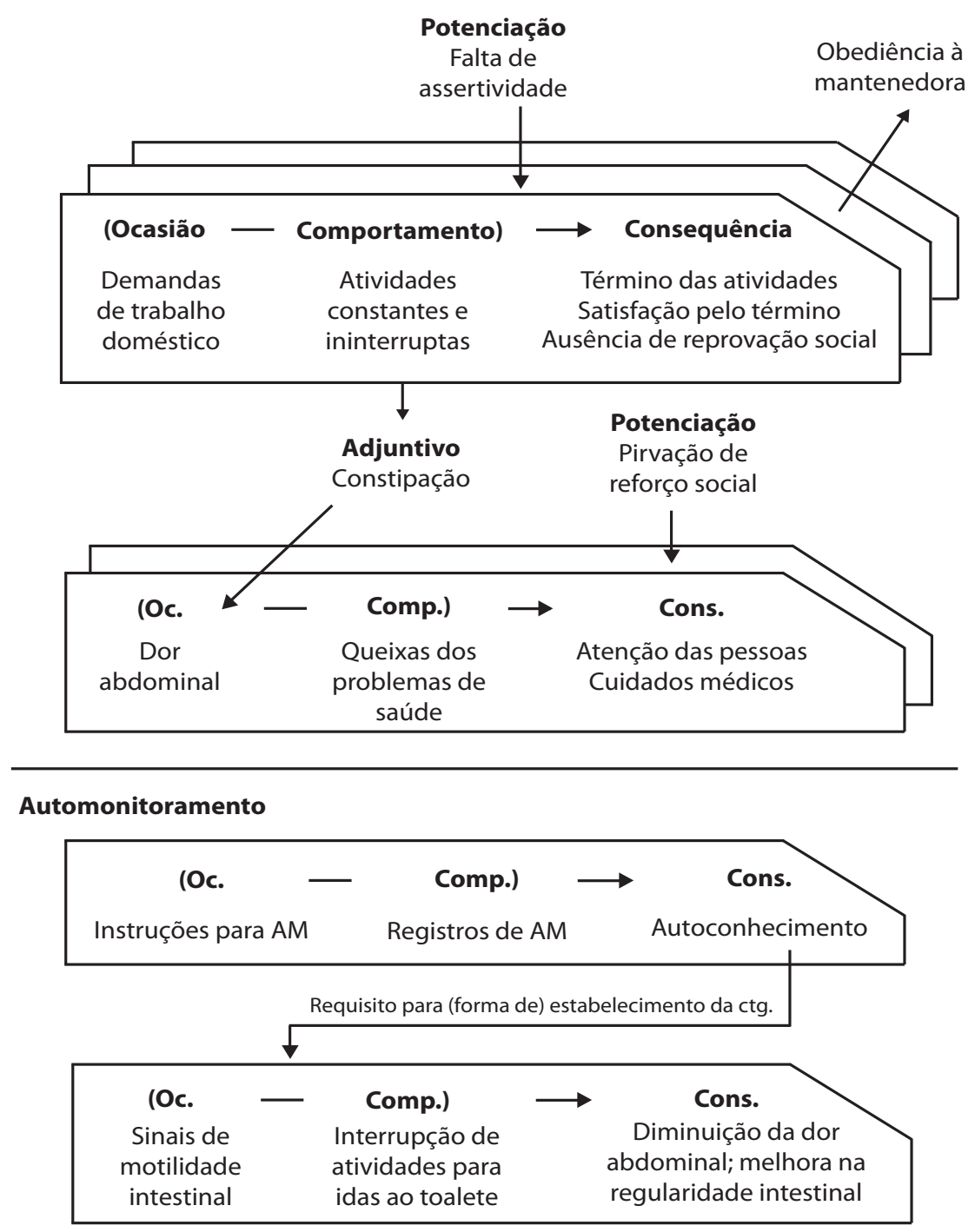

Figura 3. Possibilidades de contingências relacionadas às atividades diárias e aos sintomas de SII da participante Penélope.

Springs \& Johnson, 1992) e esquema de reforçamento em FR ajustado para gerar intervalos fixos entre reforços (Wyle, Layng \& Meyer, 1993).

O padrão de Penélope de realização ininterrupta das atividades diárias se assemelha a comportamentos mantidos por esquemas de razão, sendo as tarefas/atividades completas, os reforços. A interrupção das atividades que começou a ocorrer com o uso do AM possivelmente aumentou o intervalo entre reforços, o que, como demonstrado por Wyle, Layng e Meyer (1993), é uma variável importante na indução da motilidade intestinal. A Figura 3 apresenta um diagrama de uma possível análise funcional dos sintomas de SII da participante Penélope. Esse diagrama é baseado no paradigma da expansão da contingência para compreensão do comportamento, conforme Gimenes, Bohm e Kanamota (2010).

A parte superior da Figura 3 representa o padrão inicial das atividades diárias da participante Penélope. A falta de assertividade atuava como variável potenciadora para a contingência em que as demandas de trabalho doméstico eram ocasião para o comportamento de realizar as atividades de forma constante e ininterrupta. Este padrão de comportamento tinha como conseqüências o término das atividades, a satisfação pelo término e a ausência de reprovação social. Essa contingência provavelmente foi estabelecida por uma história de obediência da participante à sua mantenedora. A contingência induzia a constipação intestinal que, por sua vez, produzia dor abdominal. Esta atuava como ocasião em outra contingência, na qual o comportamento de queixas de problemas de saúde era consequenciado com a atenção das pessoas e cuidados médicos. Essa contingência era potencializada por privação social (falta de atenção em outras situações).

A parte inferior da Figura 3 representa as contingências que entraram em vigor com o procedimento de AM. As instruções para o AM atuavam como ocasião para o comportamento de produzir registros de $\mathrm{AM}$, que tinha como conseqüência o autoconhecimento, isto é, uma percepção mais acurada das relações entre suas atividades e o funcionamento intestinal. 
Segundo a proposição de Goldiamond, o autoconhecimento pode ser entendido como um requisito para o (ou forma de) estabelecimento de outra contingência (Gimenes, Bohm \& Kanamota, 2010; Schwartz \& Goldiamond, 1975). Nessa contingência a ocasião eram os sinais de motilidade intestinal, e comportamento de interrupção de atividades para idas ao toalete era consequenciado pela diminuição da dor abdominal e a melhora na regularidade intestinal.

Por fim, conclui-se que, para este caso de constipação, ocorreu uma melhora não programada nos sintomas como um efeito de reatividade ao AM. Inicialmente as atividades diárias da participante aconteciam de forma ininterrupta; a partir dos registros de AM a participante aprendeu a reconhecer a interação de suas atividades e o funcionamento intestinal, o que a levou a realizar interrupções dessas atividades quando dos sinais de motilidade, aumentando assim a freqüência de evacuação e uma melhor regularização intestinal.

\section{Referências}

Abrams, D. B., \& Wilson, G. T. (1979). Self-monitoring and reactivity in the modification of cigarette smoking. Journal of Consulting and Clinical Psychology, 47, 243-251.

Avanutri (2008). Avanutri: sistema de avaliação nutricional (Versão 3.1). Rio de Janeiro: Avanutri Informática LTDA.

Barton, K. A., Blanchard, E. B., \& Veazey, C. (1999). Selfmonitoring as an assessment strategy in behavioral medicine. Psychological Assessment, 11(4), 490-497.

Bezerra, P. C. (2001). Registro alimentar e auto-monitoramento: uma contribuição para o controle da obesidade. Dissertação de Mestrado, Universidade de Brasília, Brasília.

Bohm, C. H. (2009). Síndrome do intestino irritável: um exercício em análise funcional do comportamento. Dissertação de Mestrado, Universidade de Brasília, Brasília.

Bohm, C. H., \& Gimenes, L. S. (2008). Automonitoramento como técnica terapêutica e de avaliação comportamental. Revista Psicolog, 1, 88-100.

Bohm, C. H., \& Gimenes, L. S. (2009). O uso do automonitoramento na análise do comportamento. In R. C. Wielenska (Ed.), Sobre Comportamento e Cognição: desafios, soluções e questionamentos (Vol. 23, pp. 230-238). Santo André: ESETec.

Britto, I. A. G. S., \& Duarte, A. M. M. (2004). Transtorno de pânico e agorafobia: Um estudo de caso. Revista Brasileira de Terapia Comportamental e Cognitiva, 6(2), 165-172.

Falk, J. L., \& Kupfer, A. S. (1998). Adjunctive behavior: applications to the analysis and treatment of behavior problems. In W.T. O'Donohue (Ed.), Learning and behavior therapy (pp. 334351). Needham Height: Allyn \& Bacon.

Frederiksen, L. W. (1975). Treatment of ruminative thinking by selfmonitoring. Journal of Behavior Therapy and Experimental Psychiatry, 6, 258-259.

Gimenes, L. S. (1997). Comportamento adjuntivo: Um possível modelo para a análise e intervenção em problemas de saúde. In R. A. Banaco (Ed.), Sobre comportamento e Cognição (Vol. 1, pp. 395-403). São Paulo: ARBytes.

Gimenes, L. S., Andronis, P. T., \& Goldiamond, I. (1987). Estudo de algumas variáveis de procedimento na defecação induzida por esquemas de reforçamento. Psicologia: Teoria e Pesquisa, 3(2), 104-116.
Gimenes, L. S., Andronis, P. T., \& Goldiamond, I. (1988). Defecação induzida por esquema múltiplo de reforçamento. Ciência $e$ Cultura, 40(11), 1121-1123.

Gimenes, L. S., Andronis, P. T., \& Layng, T. V. (2005). O questionário construcional de Goldiamond: Uma análise nãolinear de contingências. In H. J. Guilhardi \& N. C. Aguirre (Eds.), Sobre comportamento e Cognição (Vol. 15, pp. 308322). Santo André: ESETec.

Gimenes, L. S., Bohm, C. H., \& Kanamota, J. S. V. (2010). Análise funcional no contexto da saúde. In M. M. C. Hubner, M .R. Garcia, P. R. Abreu, E. N. P. Cillo, \& P.B. Faleiros. (Eds.), Sobre Comportamento e Cognição. (Vol. 26, pp. 26-38). Santo André: ESETec.

Gimenes, L. S., Brandão, A. M., \& Benvenuti, M. F. (2005). Comportamento adjuntivo: da pesquisa à aplicação. In J. Abreu-Rodrigues \& M. R. Ribeiro (Eds.), Análise do Comportamento: pesquisa, teoria e aplicação (pp. 99-112). Porto Alegre: ArtMed.

Hayes, S. C., \& Nelson, R. O. (1983). Similar reactivity produced by external cues and self-monitoring. Behavior Modification, 7(2), 183-196.

Korotitsch, W. J., \& Nelson-Gray, R. O. (1999). An overview of self-monitoring research in assessment and treatment. Psychological Assessment, 11(4), 415-425.

Latimer, P. R. (1988). Distúrbios gastrintestinais funcionais: Um enfoque de medicina comportamental (B. Maierovitch, Trad.). São Paulo: Andrei Editor (Obra original publicada em 1983).

Latner, J. D., \& Wilson, G. T. (2002). Self-monitoring and the assessment of binge eating. Behavior Therapy, 33(3), 465-477.

Leibbrand, R., \& Hiller, W. (2003). Cognitive behavior therapy for functional gatrointestinal disorders: is group treatment effective? Acta Neuropsychiatrica, 15, 242-248.

Levy, R. L., Cain, K. C., Jarrett, M., \& Heitkemper, M. M. (1997). The relationship between daily life stress and gastrointestinal symptoms in women with irritable bowel syndrome. Journal of Behavioral Medicine, 20(2), 177-193.

Maletzky, B. M. (1974). Behavior recording as treatment: a brief note. Behavior Therapy, 5, 107-111.

Mizputen, S. J., Mendes, A. Magalhães, A. F. N., André, E. A., Alves, J. G., Silveira Júnior, L. S., Brito, M. V. H., \& Correia, R. A. (2006). História dos critérios diagnósticos da síndrome do intestino irritável. In F. A. Quilici, C. F. Francesconi, M. C. F. Passos, M. T. Haddad \& S. J. Mizputen (Eds.), Sindrome do intestino irritável: uma visão integrada (pp. 51-90). São Paulo: Segmento Farma.

Mundim, M. B., \& Bueno, G. N. (2006). Análise comportamental em um caso de dependência à nicotina. Revista Brasileira de Terapia Comportamental e Cognitiva, 8(2), 179-191.

Nelson, R. O., \& Hayes, S. C. (1981). Theoretical explanations for reactivity in self-monitoring. Behavior Modification, 5, 3-14.

Núcleo de Estudos e Pesquisas em Alimentação da Universidade de Campinas (2006). Tabela brasileira de composição dos alimentos ( $2^{\mathrm{a}}$ edição). Campinas: Universidade de Campinas.

Oliveira, M. A., \& Duarte, A. M. M. (2004). Controle de respostas de ansiedade em universitários em situações de exposições orais. Revista Brasileira de Terapia Comportamental e Cognitiva, 6(2), 183-200. 
Passos, M. C. F., Filho, A. L., Pontes, E. L., Amarante, H. M. B. S., Eisig, J. N., \& Almeida, J. R. (2006). Introdução. In F. A. Quilici, C. F. Francesconi, M. C. F. Passos, M. T. Haddad \& S. J. Mizputen (Eds.), Sindrome do intestino irritável: uma visão integrada (pp. 9-22). São Paulo: Segmento Farma.

Philippi, S. T. (2002). Tabela de composição de alimentos: suporte para decisão nutricional ( $2^{\mathrm{a}}$ edição). São Paulo: Coronário.

Polaha, J., Allen, K., \& Studley, B. (2004). Self-monitoring as an intervention to decrease swimmers' stroke counts. Behavior Modification, 28(2), 261-275.

Rayfield, F., Segal, M., \& Goldiamond, I. (1982). Schedule-induced defecation. Journal of the Experimental Analysis of Behavior, 38(1), 19-34.

Schwartz, A., \& Goldiamond, I. (1975). Social casework: a behavioral approach. New York: Columbia University.

Tarrier, N., Sommerfield, C., Reynolds, M., \& Pilgrim, H. (1999). Symptom self-monitoring in the treatment of posttraumatic stress disorder. Behavior Therapy, 30, 597-605.
Whitehead, W. E., \& Bosmajian, L. S. (1982). Behavioral medicine approaches to gastrointestinal disorders. Journal of Consulting and Clinical Psychology, 50(6), 972-983.

Wyle, A. M., Layng, M. P., \& Meyer, K. A. (1993). Scheduleinduced defecation by rats during ratio and interval schedules of food reinforcement. Journal of the Experimental Analysis of Behavior, 60(3), 611-620.

Wylie, A. M., Springs, R., \& Johnson, K. S. (1992). Scheduleinduced defecation: no-food and massed-food baselines. Journal of the Experimental Analysis of Behavior, 58(2), 389-397.

Recebido em 08.12.2009

Primeira decisão editorial em 02.03.2011

Versão final em 17.08.2011

Aceito em 16.04.2012 